\title{
Multifunctional MOFs Based on Imidazoletricarboxylic Acid for Gas Adsorption, Sensing and Catalysis
}

\section{Sharad Kumar Sachan, Sarita Tripathi, Namita Singh, Renganathan Srirambalaji and Ganapathi Anantharaman*}

\section{Department of Chemistry, Indian Institute of Technology Kanpur, Kanpur-208016 garaman@iitk.ac.in}

Porous materials such as zeolites have made an indispensable impact in day-to-day life to commercial applications. The structural rigidity created by primary $\left[\mathrm{SiO}_{4}\right]^{4-}$ and $\left[\mathrm{AlO}_{4}\right]^{3-}$ units and associated with the framework stability are one of the prime criteria for its vast applications. At times the rigidity of the structure, difficulties in functional properties and nuances of the synthetic procedure. ${ }^{1}$ Alternatively, materials made of coordination polymers (CPs) or metal-organic frameworks (MOFs) have gained enormous attention due to their simplicity in preparation, structural diversity, and the applications in gas-adsorption, separation of small molecules, catalysis, sensing of small molecules to hazardous materials, drug delivery, nonlinear optics, proton conductivity, and other biomedical related processes. These prominences of $\mathrm{MOF} / \mathrm{CPs}$ in the last three decades have stimulated a colossal amount of research interests in the study of frameworks having multifunctional properties. The diversity in applications is mainly attributed to the robustness of the MOFs against hydro- and thermal stability under different $\mathrm{pH}$ solutions besides maintaining the crystallinity and their porosity. In addition, in the presence of Lewis acidic/basic sites, these MOFs were potentially used as catalysts for various organic transformations. ${ }^{1-3}$ In this talk, the preparations of some mixed metal oxides and CPs/MOFs derived imidazole-based carboxylic acid systems and metal substrates will be presented. In addition, the properties of these systems in the areas of gas adsorption, luminescence-based sensing/remediation of hazardous materials, and catalysis will be presented. ${ }^{4,5}$
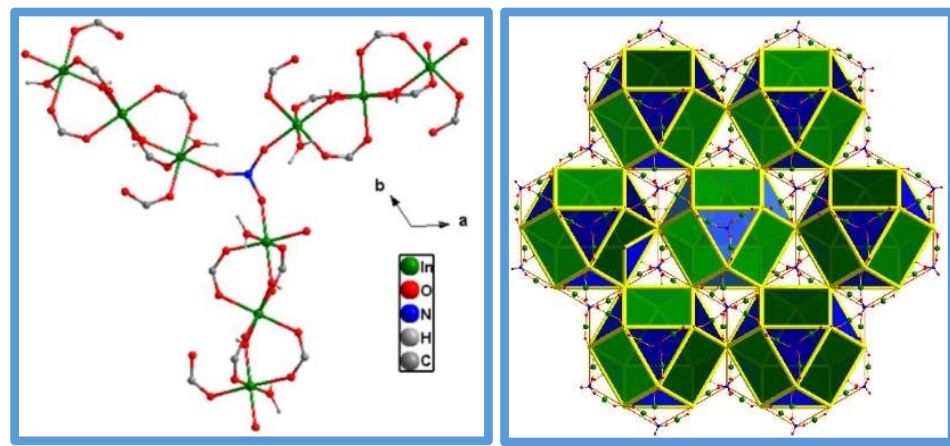

Figure: SBU (left) and 3D cuboctahedral structure of Indium

1. (a) Kreno, L. E., Leong, K., Farha, O. K., Allendorf, M., Van Duyne, R. P., \& Hupp, J. T. (2012) Chem. Rev. 112, 1105. (b) Kitagawa, S., \& Kitaura, R.; Noro, S. (2004) Angew. Chem., Int. Ed. 43, 2334.

2. (a) Huang, Y.-B., Liang, J., Wang, X.-S., \& Cao, R. (2017) Chem. Soc. Rev. 46, 126. (b) Zhou, H.-C., Long, J. R., \& Yaghi, O. M. (2012) Chem. Rev. 112, 673

3. (a) Wang, J., Liu, X., \& Feng, X. (2011) Chem. Rev. 111, 6947. (b) Reinares-Fisac, D., Aguirre-Díaz, L. M., Iglesias, M., Snejko, N., Gutiérrez-Puebla, E., Monge, M. Á., \& Gándara, F. A. (2016) J. Am. Chem. Soc. 138, 9089.

4. (a) Penke. Y. K., Anantharaman, G., Ramkumar, J., \& Kar, K. K. (2019) J. Hazard. Mater. 354, 519. (b) Penke. Y. K., Anantharaman, G., Ramkumar, J., \& Kar, K. K. (2017) ACS appl. Mater. Interfaces. 9, 11587. (c) Penke, Y. K., Anantharaman, G., Ramkumar, J., \& Kar, K. K. (2015) RSC Adv., 6, 55608.

5. (a) Tripathi, S., \& Anantharaman, G. (2015) CrystEngComm, 17, 2754. (b) Mohapatra, C., Tripathi, S., Chandrasekhar, V., \& Anantharaman, G. (2014) Cryst. Growth. Des., 14, 3182. (c) Sachan, S. K., \& Anantharaman, G. (2021) Inorg. Chem., 60, 9238.

Keywords: Indium-organic framework (InOF); Nitrate binding; $\mathrm{CO}_{2}$ fixation; multi-component synthesis; 2,4,6trinitrophenol (TNP)

Authors thank Science and Engineering Research Board (SERB, India, No. SB/S1/IC-49/2012), for funding. Authors also thank CSIR (SKS \& ST), \& IIT Kanpur (NS \& RS) for the doctoral fellowship, and the infrastructural facilities (IITK). 